\title{
Recognition and Empirical Research on Key Influencing Factors of Low Carbon Development for Logistics Company
}

\author{
Xiang-Yun Duan, ${ }^{1}$ Hsiu-Jung Chou, ${ }^{2}$ and Shuenn-Ren Cheng ${ }^{2}$ \\ ${ }^{1}$ Department of Modern Service, Zhejiang Shuren University, No. 8, Shuren Street, Gongshu District, Hangzhou, \\ Zhejiang 310015, China \\ ${ }^{2}$ Department of Business Administration, Cheng Shiu University, No. 840, Chengcing Road, Niaosong District, \\ Kaohsiung City 83347, Taiwan
}

Correspondence should be addressed to Hsiu-Jung Chou; hjc724@ms13.hinet.net

Received 1 July 2014; Accepted 15 September 2014

Academic Editor: Yunqiang Yin

Copyright ( $) 2015$ Xiang-Yun Duan et al. This is an open access article distributed under the Creative Commons Attribution License, which permits unrestricted use, distribution, and reproduction in any medium, provided the original work is properly cited.

\begin{abstract}
The questionnaire paper used was work out by modifying the existing mature research scale and interviewing the experts and enterprises. The purpose of this study is to explore the key influencing factors of low carbon development for logistics companies by using the data from the questionnaire, which might contribute to further investigation of low carbon development pathway. Through correlation and stepwise regression analysis, differences between influencing factors and impact-degree were found since specific environmental behaviors of low carbon logistics might vary significantly. The driving factor of low carbon input comes from external points such as government and public external pressure, so the low carbon input is driven by an outside force. Yet, low carbon operation is significantly affected by internal factors such as low carbon behavior capacity, which is driven by an inside force.
\end{abstract}

\section{Introduction}

Although the low carbon economy has put forward ten years, the pollution of basic vital materials such as water, air, and food is still reported, indicating a big gap between the low carbon actual and target. The reduction targets and absolute cap of carbon were established by the international community, with low carbon logistics remaining as a major concern of large energy consumption industry. According to the report of World Economic Forum in 2009, so far the overall logistics industry still counted for 5.5 percent of global greenhouse gas emission. How to achieve low carbon development for logistics enterprise is not only a question of economics theory and method, but also an important policy decision, since the carbon pollution analysis and low carbon governing policies were made on the basis of making the low carbon logistics behavior, influencing factors of environmental behavior, and impact paths clear.

Scholars have already started the research of low carbon logistics from the industry and enterprise level. Industry research mainly focuses on transportation department of logistics and the low carbon growth pathways of transportation sector of the logistic industry that was studied from macroscopic aspect of modeling urban, infrastructure, and spatial determinants of mobility [1]. It was found that the transport sectors are incapable of action on standard pricing and have long relied on public facilities. In order to reduce emissions of transport sector, public facilities should be designed by controlling the mobility measures such as reducing the movement intensity, investing in public mode, and reengineering the production process to low mobility. The enterprise environmental management of transport department was also studied [2] and it was found that the environmental management performance is obviously different between large and small land transportation logistics enterprises, and small land transportation logistics enterprises need to improve environmental performance compared with large enterprises. These researches adopt similar research ideas, which mainly focus on the research sector and enterprise partial characteristics. According to the Carbon Disclosures Project Supply Chain Report in 2011, there are over 50 percent of average corporation's carbon 
emissions that typically result from its supply chain. It is well known that logistics is the important part of a supply chain, while the research on enterprises' environmental behavior and influencing factors on this part is yet on the exploration stage [3]. Based on the situations mentioned above, this paper began from the systematic literatures survey of related field and worked out the questionnaire by modified from well-established foreign scale and through the method of expert interview and enterprise interview and then studied characteristics of low carbon logistics behavior as well as the effect of various social and individual enterprises variables on low carbon logistics behavior by using the data from the questionnaire. The purpose of this study is to explore the key influencing factors of low carbon development for logistics companies, which might contribute to make further investigation of low carbon development pathway.

\section{Literature Review and Hypotheses}

From the viewpoint of utility, low carbon logistics is a kind of environmental behavior. Scholars have provided many classical research framework about environmental behavior and its influencing factors, which includes the theory of planned behavior (TPB), the value-belief-norm (VBN) theory, and $\mathrm{ABC}$ theory model. The theory of planned behavior (TPB) was built on the theory of reasoned action (TRA) by Ajzen, with perfect explanatory power to the decisionmaking process of the general behavior. TPB became the classic theory of social psychology and was applied to predict and study the behavior. According to the theory of planned behavior, behavioral intention is the direct factors to determine the behavior, which act successfully only under the circumstances of conditions that behavior ability, opportunity, and resources were controlled by an individual, while the behavioral attitude, subjective norms, and perceived behavior control are three major factors to determine the behavioral intention. The stronger behavior attitude, the more support from others, the bigger perceived behavior control, and the behavior intention become greater, and vice versa [4-6].

The value-belief-norm (VBN) theory established by Stern focused on the formation process of environmental action. On the basis of explaining the types and role of environment value, the functional relations between the subjective variables of values, beliefs, norms, and the positive environmental behavior were defined and the results indicate that the environment attitude was affected by environmental value system, environmental beliefs affecting environmental norms and then the environment behavior was formed. The continuous effects of environmental values, beliefs, and norms can explain the environmental behavior [7-9]. It was confirmed by many empirical researches since this theory has been issued and opened up a new perspective for the study of environmental behavior.

The scholars of Ajzent and Stern have focused on the impact of norms and beliefs on environmental behavior. Although the influence pathway is different, norms and beliefs are all the internal cognitive variables. Focusing on the role of external factors by Guagnano et al., the famous $\mathrm{ABC}$ theory model believes that the effect of attitude (A) and circumstances $(\mathrm{C})$ on behavior (B) depends on the relative value rather than individual value. It was found that the environmental behaviors generally occur when the external factors are positive as a result of joint action of behavior attitudes and exterior condition; there is the strongest relationship between environmental behaviors and attitudes when the influence of external conditions are neutral, and exterior condition plays an adjustment role in environmental attitudes and behaviors [10].

Many scholars have studied the influential variables based on the above classical research framework. The direction of research includes the relationship among the environmental attitude, personality factors, situational factors, and the environmental behavior. Specifically, it was listed as follows.

2.1. The Relationship between Environmental Attitude and Environmental Behavior. The scholars of new institutionalism theory fully have recognized the factors of external specification, values, and tradition in the system environment and believed both of them bring convergence pressure to organization in the field. Kotzab et al. [11] have developed a scale to evaluate the environmental supply chain initiatives of the world's largest 100 retailing companies and found that environmental supply chain management can be characterized as green operations oriented; environmental sustainability initiatives of supply chain include eight categories and fundamental environmental attitude is the most important one. The environmental attitudes were defined as the general attention and beliefs on the ecological environment in the new environmental paradigm, and NEP scale as new environmental paradigm scale was put forward [12]. After that, the NEP scale was used widely as a tool to measure the environment. Many scholars have investigated the relationship between environmental attitudes and behaviors by using NEP scale and found that there is significant correlation between environmental attitudes and behavior, and the positive environmental attitude played a significant role in promoting the environmental behavior [13, 14]. As for environmental attitudes, scholars have consistently supported the positive effect of environmental responsibility and values on environment behavior. VBN theory clearly points out that the environmental value is an important antecedent of environmental behavior [8] and there are differences in the function routes of environmental responsibility. There are mainly two kinds of view of function route and the details are as follows: one's opinion tends to believe that environmental responsibility directly affects the environment behavior [9, 15]; another thinks that environmental responsibility indirectly affects the environment behavior through intermediary variable $[16,17]$.

Based on the above analysis, the first set of assumptions of this research was put forward:

H1: the environmental attitude of logistics enterprise remarkably influences the behavior of low carbon logistics;

H1a: the stronger the environmental value of logistics enterprise is, the more conducive it was to implement the low carbon logistics; 
H1b: the stronger the environmental responsibility of logistics enterprise is, the more conducive it was to implement the low carbon logistics.

\subsection{The Relationship between Personality Factors and Environ-} mental Behavior. Scholars that studied the aspects of organization and management theory have focused on internal enterprise and the relationship between personality factors and environmental behavior. There are three research ideas: the first is the attitude-behavior route. Taking behavior as the guidance, researchers have detected that the environmental behavior willingness is the direct influential factor or high latent variables for environmental behavior through the empirical research on environmental behavior. The strong positive correlation between willingness of environmental behavior and ecological behavior was found through the investigation of 3000 sample of transport association in Switzerland, and its explanatory power reaches 75 percent [18]. Some studies have found that the higher the environmental awareness of enterprise members, especially of the leaders, the greater the possibility of using nice environmental behavior $[19,20]$. The second is the resource-abilitybehavior route. Based on the consideration of resources, it was found out that the complementary resources and capabilities of enterprises firstly affected the business ethical attitudes of manager and further impacted the enterprises' environmental strategy and related behavior [21]. The study was concerned with self-perception and found that perceived environmental uncertainty has a negative effect on corporate environmental behavior, by taking the small and medium enterprises in Taiwan as samples [22]. The third is psychology-behavior route. Some researcher paid attention to the psychological forming process of environmental behavior and discovered that company tends to make environmental behavior in the situation of deterrence and group psychology other than attitudes to better explain the environmental behavior [23].

According to the above analysis, the second set of hypotheses in this study was proposed:

$\mathrm{H} 2$ : personality variables of logistics enterprise significantly affect the low carbon logistics behavior;

$\mathrm{H} 2 \mathrm{a}$ : the stronger the environmental group psychology of logistics enterprise is, the more helpful it was to carry out low carbon logistics;

$\mathrm{H} 2 \mathrm{~b}$ : the richer the low carbon related knowledge of logistics enterprise is, the more helpful it was to carry out low carbon logistics;

$\mathrm{H} 2 \mathrm{c}$ : the stronger the low carbon behavior willingness of logistics enterprise is, the more helpful it was to carry out low carbon logistics;

$\mathrm{H} 2 \mathrm{~d}$ : the stronger the self-efficacy of logistics enterprise is, the more helpful it was to carry out low carbon logistics;

$\mathrm{H} 2 \mathrm{e}$ : the stronger the low carbon behavior capability of logistics enterprise, the more helpful it was to carry out low carbon logistics.
2.3. The Relationship between Situational Factors and Environmental Behavior. The responsible environmental behavior model was proposed by Hines et al., it has not only verified the significant impact of action technology, action strategy knowledge, and environmental knowledge on the environmental behavior, but also put forward that the situational factors such as economic condition, social pressure and whether or not have an opportunity to engage in environmental behavior was an important external cause of environment behavior [16]. Scholars have explored the influence of external environment pressure on the enterprise environment from different angles; it was found that financial and human resources play an important role in companies' implementation of reverse logistics, whereas tangible resources do not have much influence on the practice [24]; regulation system of environment and strong regulation by government can affect the environment behavior and force enterprises to make cost internalization of external conditions [25]; the pressure generated by social norms has significantly influenced on the environmental behavior [26]; logistics companies' willingness to adopt RFID technology is significantly influenced by the explicitness and accumulation of technology, organizational encouragement for innovation, quality of human resources, and governmental support [27]. And the technology progress and maturity play an effective role of resistance to the emission of pollutants [28].

Based on the above analysis, the third set of hypothesis in this study was raised:

H3: the situational factors have significantly impacted on low carbon logistics behavior;

H3a: the more the low carbon economic cost paid by logistics enterprises is, the more beneficial it was to promote low carbon logistics;

$\mathrm{H} 3 \mathrm{~b}$ : the greater the low carbon social constraints faced by logistics enterprises are, the more beneficial it was to promote low carbon logistics;

$\mathrm{H} 3 \mathrm{c}$ : the more the guiding influence of low carbon policies and regulations is, the more beneficial it was to promote low carbon logistics;

H3d: the higher the low carbon technology maturity is, the more beneficial it was to promote low carbon logistics.

\section{Design of Scale}

The scale used in this study arises from the two aspects: one is modified from well-established scale from foreign countries and indigenized based on the actual situation of logistics enterprises in China, and the other is a developed measurement scale by defining and operating the research variables through the expert interviews and enterprise interview. Since there are mature scales to measure variables such as environmental values, environmental responsibility, self-efficacy, 
low carbon behavior intention, economic cost, social norms, policies and regulations, and technical maturity in foreign countries, this study uses them after local modification. While the variables with local characteristics such as group psychology and low carbon behavior capability have not been introduced into the study of enterprises' environment behavior in foreign countries, the scale was developed combined with the enterprise and expert interviews. Since there is no mature scale to study low carbon logistics behavior, this paper developed the measurement items from the operation angle and divided it into two aspects of low carbon input and low carbon operation by taking the suggestion of expert and enterprise as the reference.

To ensure that the questionnaire has good content validity, presurvey as to the initial questionnaire was conducted on a smaller scale. The validity and efficiency of initial questionnaire were tested by using the SPSS17.0 statistical software, and the variable scale in which alpha coefficient is lower than 0.5 was redesigned. The final questionnaire has been formed after deleting the inappropriate indexes scale that factor's alpha coefficient is less than 0.6 and correlation coefficient of the item total is less than 0.3.

The final questionnaire contains a total of three parts. The first part is the scale of low carbon logistics behavior with 10 items, which focuses on low carbon investment behavior and low carbon operation behavior of logistics enterprises. These two variables were confirmed by interviews with entrepreneur during the first period of investigation. The second part is the scale of influence factors of low carbon logistics with 41 items, including environmental attitude, personal characteristics of enterprises, and situation factor. There into, the environmental attitudes include two variables of environmental values and environmental responsibility, it was respectively consulted the scale of Dunlap et al., [29] and Gärling et al., [17] in the process of scaled designed, and modified by domestication. The personality factors include five variables of low carbon related knowledge, low carbon behavior willingness, environmental group psychology, selfefficacy, and low carbon behavior capability; it referred to the scaled of Frick et al. [30], Chan [31], Sherer et al. [32], and Tanner and Kast [33] when the scale was designed; the economic cost, social norms, policies and regulations, and technical maturity are four variables of situational factors, designed by using the scale of Stern $[8,9]$ for reference. The third part is the basic personal information with 8 items. The five-point Likert scale was used in both parts of one two in the questionnaire.

The formal questionnaires were handed out by telephone, email, and visits to enterprises to investigate 198 logistics enterprises in Zhejiang province. The type of enterprise covers the transport, storage, and integrated logistics enterprise and the research objects include executives and employees of logistics enterprise. In this study, 550 questionnaires were issued and 400 were retrieved during the period of investigation, 305 questionnaires were available in it after a screening process, and the rate of recovery of scale is 72.7 percent and valid by 55.45 percent.

\section{Empirical Analysis}

4.1. Scientific Test of Scale. The first thing is to test the construct validity. First of all, both KMO value and Bartlett's spherical of four variables needed testing; the four variables include low carbon logistics behavior, environment attitude of enterprise, enterprises' personality characteristics, and situational factors. The results of the test show that KMO values of four variables were $0.856,0.821,0.704$, and 0.804 , all above 0.7 , and Bartlett's spherical values of the four variables have been verified by Bartlett's test. The total variance was $60.93 \%, 65.68 \%, 76.97 \%$, and $72.20 \%$; that is to say, the scale is suitable for factor analysis. In the second place, orthogonal rotation of the maximum variance was made on the four variables by using principal component analysis. According to the standard of characteristic roots greater than 1, the variables of both low carbon logistics behavior and enterprise environment attitude can be extracted 2 main factors, the variables of corporate personality characteristics can be extracted 5 main factors, and situational variables can be extracted 4 main factors. Last, but not least, it is necessary to compare factor loading. It is found that the loading of all measurements on their own respective factors is greater than 0.5 ; nevertheless, the loading on the other factors is less than 0.5 . The results indicated that both convergent validity and discriminant validity of the scale are able to meet the requirements and construct validity is well.

In addition to construct validity testing, reliability testing was also needed. The main work of reliability test is to analyze Cronbach's alpha coefficient of the scale. Cronbach's alpha coefficients of four variable of low carbon logistics behavior, environment attitude of enterprise, enterprises' personality characteristics, and situational factors were $0.735,0.749,0.872$ and 0.815 , all of them were above 0.6 , which show that the scale has good reliability.

4.2. The Descriptive Analysis of the Questionnaire. The descriptive analysis of the variables was shown in Table 1. From the description of the low carbon logistics behavior and impact factors, the mean of low carbon input and operation is 3.83 and 3.27 , that is to say, the mean of low carbon logistics behavior below 4, which indicates that low carbon action level of logistics enterprises is still in the state of between half-done and mostly done. Since the score is low in general, the implementation of environment behavior of low carbon logistics is not satisfactory. Compared with the implementation of two kinds of environmental behavior, low carbon inputs are better than low carbon operations. Logistics enterprises pay more attention to low carbon input compared with low carbon operation, so the low carbon operation is relatively weak. The reason might be correlated with the degree of environmental responsibility, low carbon related knowledge, and low carbon behavior ability, while both of them get the lowest score in the influence factors.

The situational factors get the highest scores among the three influencing factors. The mean of variables of situational factors besides economic cost is above 4 , which implies that the logistics enterprises recognize the effect of social norms, policies and regulations, and technology maturity on low 
TABLE 1: The descriptive statistical analysis of variables.

\begin{tabular}{lccccc}
\hline Variable & Mean & Standard deviation & Variable & Mean & Standard deviation \\
\hline Low carbon input & 3.83 & 0.47 & Self-efficacy & 3.86 & 0.1 \\
Low carbon operation & 3.27 & 0.59 & Low carbon capability & 3.21 & 0.33 \\
Environmental value & 3.69 & 1.06 & Economic cost & 3.91 & 0.35 \\
Environmental responsibility & 3.41 & 0.15 & Social norm & 4.14 & 0.27 \\
Group psychology & 3.75 & 0.29 & Policies and regulations & 4.18 & 0.19 \\
Low carbon knowledge & 3.45 & 0.22 & Technology maturity & 4.23 & 0.16 \\
Low carbon behavior intention & 3.94 & 0.17 & & & \\
\hline
\end{tabular}

TABLE 2: The correlation matrix between low carbon logistics behavior and influence factors.

\begin{tabular}{|c|c|c|c|c|c|c|c|c|c|c|c|c|c|}
\hline & 1 & 2 & 3 & 4 & 5 & 6 & 7 & 8 & 9 & 10 & 11 & 12 & 13 \\
\hline Low carbon input & 1 & & & & & & & & & & & & \\
\hline Low carbon operation & 0.046 & 1 & & & & & & & & & & & \\
\hline Environmental value & $0.351^{* *}$ & $0.265^{* *}$ & 1 & & & & & & & & & & \\
\hline $\begin{array}{l}\text { Environmental } \\
\text { responsibility }\end{array}$ & $0.288^{* *}$ & $0.304^{* *}$ & $0.323^{* *}$ & 1 & & & & & & & & & \\
\hline Group psychology & $0.300^{* *}$ & $0.424^{* *}$ & 0.06 & 0.041 & 1 & & & & & & & & \\
\hline Low carbon knowledge & $0.237^{* *}$ & $0.167^{* *}$ & 0.044 & -0.044 & 0.009 & 1 & & & & & & & \\
\hline $\begin{array}{l}\text { Low carbon behavior } \\
\text { intention }\end{array}$ & $0.170^{* *}$ & $0.533^{* *}$ & $0.213^{* *}$ & $0.654^{* *}$ & $0.386^{* *}$ & $0.306^{* *}$ & 1 & & & & & & \\
\hline Self-efficacy & $0.170^{* *}$ & $0.563^{* *}$ & 0.076 & 0.048 & $0.349^{* *}$ & 0.108 & $0.235^{* *}$ & 1 & & & & & \\
\hline Low carbon capability & $0.173^{* *}$ & $0.588^{* *}$ & 0.079 & $0.249^{* *}$ & $0.139^{*}$ & $0.427^{* *}$ & $0.392^{* *}$ & $0.460^{* *}$ & 1 & & & & \\
\hline Economic cost & $0.103^{*}$ & $0.165^{* *}$ & $0.125^{*}$ & -0.057 & $0.387^{* *}$ & -0.087 & $0.205^{* *}$ & $0.307^{* *}$ & $0.134^{*}$ & 1 & & & \\
\hline Social norm & $0.388^{* *}$ & $0.448^{* *}$ & $0.372^{* *}$ & $0.254^{* *}$ & -0.002 & -0.078 & $0.411^{* *}$ & $0.335^{* *}$ & $0.253^{* *}$ & $0.179^{* *}$ & 1 & & \\
\hline Policies and regulations & $0.465^{* *}$ & $0.374^{* *}$ & $0.279^{* *}$ & $0.311^{* *}$ & $0.405^{* *}$ & $0.318^{* *}$ & $0.593^{* *}$ & 0.11 & $0.347^{* *}$ & $0.353^{* *}$ & $0.379^{* *}$ & 1 & 1 \\
\hline Technology maturity & $0.252^{* *}$ & $0.235^{* *}$ & $0.154^{* *}$ & 0.009 & $0.592^{* *}$ & $-0.195^{* *}$ & $0.208^{* *}$ & $0.351^{* *}$ & 0.032 & $0.539^{* *}$ & 0.112 & $0.389^{* *}$ & 1 \\
\hline
\end{tabular}

Double star means that the significant correlation exits at 0.01 significant levels and single star exists at 0.05 significant levels.

carbon environmental action, and the external situational factors have significant influence on the behavior of low carbon logistics. The lowest score of mean among the personality factors is low carbon behavior ability with the score of 3.21, showing that the ability of logistics can deal with the low carbon business half-done. Low carbon knowledge is related with the variable of low carbon capability, and the mean of low carbon knowledge is 3.45 , which shows that enterprises generally know something about low carbon and should strengthen knowledge learning to enhance the ability of low carbon behavior. The low carbon behavior intention gets the highest mean score of 3.94, indicating that the logistics enterprises are willing to implement low carbon development. Although logistics enterprises have strong willingness to implement the low carbon behavior under the background of low carbon economy, the absence of low carbon behavior ability and low carbon related knowledge might influence the low carbon development in varying degree. The score of mean was followed by selfefficacy at 3.86 and group psychology 3.75, reflecting that the self-cognitive ability to engage in low carbon behavior of logistics enterprises is still at a moderate level that the low carbon logistics was more or less influenced by related parties and was characteristic of conformity tendency. In the environmental factors, the mean of environmental values is
3.69 and environmental responsibility is 3.41, showing that logistics enterprises have basic environmental value but have not been updated to positive environmental value of altruism and ecological type; that is to say, although there is basic environmental awareness, it still makes further improvement on the environmental responsibility.

4.3. The Correlation Analysis of Low Carbon Logistics Behavior and Influence Factors. From the correlation relationship between low carbon logistics behavior and influencing factors (shown in Table 2), 11 influencing factors of three types of variables are correlated with low carbon logistics behavior. Besides the economic costs, other variables were positively correlated with the behavior of low carbon investment and low carbon operation at 0.01 significant levels. Furthermore, the variables of economic costs have correlation with low carbon input at 0.05 significant levels.

From the correlation degree, the variables of policies and regulations have the highest correlation with low carbon input behavior, followed by social norms, environmental values, and group psychology. The first two variables are situational factors and yet there is relatively low correlation relationship between personality factors and low carbon input. It demonstrates that the low carbon input behavior of logistics enterprises is the behavior propelled by outside force, 
TABLE 3: The regression analysis within low-carbon investment and operation as the dependent variable.

\begin{tabular}{|c|c|c|c|c|c|c|}
\hline \multirow{3}{*}{$\begin{array}{l}\text { Variable } \\
\text { The independent variable }\end{array}$} & \multicolumn{6}{|c|}{ The dependent variable } \\
\hline & \multicolumn{3}{|c|}{ Low carbon input behavior } & \multicolumn{3}{|c|}{ Low carbon operation behavior } \\
\hline & $\begin{array}{c}\text { Standardized } \\
\text { regression coefficient of } \\
\beta\end{array}$ & $t$ value & Sig. & $\begin{array}{c}\text { Standardized } \\
\text { regression coefficient of } \\
\beta\end{array}$ & $t$ value & Sig. \\
\hline (Constant) & & -0.752 & 0.006 & & -4.745 & 0 \\
\hline Environmental value & 0.16 & 4.204 & 0.000 & 0.088 & 2.393 & 0.017 \\
\hline Environmental responsibility & 0.274 & 4.522 & 0.000 & & & \\
\hline Group psychology & 0.344 & 6.352 & 0.000 & 0.331 & 7.287 & 0.000 \\
\hline Low carbon knowledge & 0.278 & 4.733 & 0.000 & & & \\
\hline Low carbon behavior intention & 0.59 & 8.85 & 0.000 & 0.331 & 7.863 & 0.000 \\
\hline Self-efficacy & 0.185 & 4.008 & 0.000 & 0.158 & 3.684 & 0.000 \\
\hline Low carbon capability & 0.096 & 1.993 & 0.047 & 0.333 & 8.09 & 0.000 \\
\hline Economic cost & 0.197 & 4.602 & 0.000 & 0.121 & 3.055 & 0.002 \\
\hline Social norm & & & & 0.263 & 6.141 & 0.000 \\
\hline Policies and regulations & 0.71 & 13.52 & 0.000 & 0.166 & 3.659 & 0.000 \\
\hline Technology maturity & 0.119 & 2.063 & 0.040 & & & \\
\hline
\end{tabular}

and external pressure from the government and the public is the driving factors to promote low carbon input behavior. External guidance and pressure are the main power to promote low carbon input of logistics enterprises, which further verified the conclusion that the variable mean reflected. There is the highest correlation relationship between low carbon operation behavior and low carbon behavior capability, followed by self-efficacy, low carbon behavior intention, social norms, and group psychology. Not only four variables of them belong to personality factors, but also the first three variables are personality factors, indicating that the low carbon operation of logistics enterprises is mainly driven by inside force and enterprise itself becomes the driving factor to promote the low carbon operation behavior. Different from the one-off behavior of low carbon input, low carbon operation is a continuous process, whose operation effect depends on the function of each enterprise, and it is obvious that the variables of enterprises individual characteristic significantly influences the low carbon operation. Otherwise, the variables with striking correlation with two categories of environmental behavior are social norms and group psychology, which obviously reflects the cultural characteristics of enterprises in china.

4.4. The Regression Analysis. Through the methods of multiple stepwise regressions, the most influential and explanatory variables of two kinds of low carbon logistics behavior were selected according to the standard coefficient values of $\beta$. In the significant test of the regression analysis, the greater the $t$ value is, the more meaningful the corresponding variables indicate, and the corresponding variable should be deleted when the $t$ value is close to zero. At less than 0.05 significant level, the main influential variables of low carbon investment behavior are policies and regulations, low carbon behavior intention, group psychology, low carbon related knowledge, environmental responsibility, economic cost, self-efficacy, environmental values, technical maturity, and low carbon behavior ability. The sorting order shows that the primary influential factors of low carbon investment behavior are the policies and regulations of external factors, whose standard coefficient value of $\beta$ is 0.71 which is far more than other variables, followed by individual features factors of enterprise. Combined with the results of correlation analysis, it was found that the low carbon investment behavior of logistics company is mainly affected by the external environment factors, and logistics enterprises will implement low carbon investment behavior when the external factors were pushed, low carbon investment intention was internalized, and the resource of software and hardware was matched, while the main influential variables of low carbon operation behavior are low carbon behavior ability, low carbon behavior intention, group psychology, social norms, policies and regulations, self-efficacy, and economic cost and environmental values. The first five variables are personality and situation factors of enterprise, and among them the first three variables are corporate personality factors which further confirm the results of correlation analysis. The implementation of low carbon operation behavior was ensured due to the internal drive of enterprise. Meanwhile, the greatest influential variables are enterprise individual characteristics, followed by situational factors. The internal resources, low carbon behavior willingness, and external force were needed to promote the low carbon operation behavior. The data was shown in Table 3 .

Summing up the above analysis, the hypotheses of $\mathrm{H} 1$, $\mathrm{H} 2$, and $\mathrm{H} 3$ are partly established. The empirical results supported the hypothesis $\mathrm{Hla}$ of $\mathrm{H} 1$, which shows that the assumption that the stronger the environmental value of logistics enterprise is, the more conducive it was to implement the low carbon logistics is valid. The hypothesis H1b was only supported for low carbon input behavior but not low carbon operation behavior; that is to say, the assumption 
that the stronger the environmental responsibility of logistics enterprise, the more conducive it was to implement the low carbon logistics is invalid. The empirical results also supported the hypotheses $\mathrm{H} 2 \mathrm{a}, \mathrm{H} 2 \mathrm{c}, \mathrm{H} 2 \mathrm{~d}$, and $\mathrm{H} 2 \mathrm{e}$ of $\mathrm{H} 2$; that is to say, the assumption of $\mathrm{H} 2 \mathrm{a}$ that the stronger the environmental group psychology of logistics enterprise is, the more helpful it was to carry out low carbon logistics were established; the assumption of $\mathrm{H} 2 \mathrm{c}$ that the stronger the low carbon behavior willingness of logistics enterprise is, the more helpful it was to carry out low carbon logistics was verified; the assumption of $\mathrm{H} 2 \mathrm{~d}$ that the stronger the self-efficacy of logistics enterprise is, the more helpful it was to carry out low carbon logistics was founded; and the assumption of H2e that the stronger the low carbon behavior capability of logistics enterprise is, the more helpful it was to carry out low carbon logistics was also testified. However, hypothesis $\mathrm{H} 2 \mathrm{~b}$ was only valid for low carbon input behavior but not low carbon operation behavior, indicating that the assumption that the richer the low carbon related knowledge of logistics enterprise is, the more helpful it was to carry out low carbon logistics is invalid. The hypothesis $\mathrm{H} 3 \mathrm{a}$ and $\mathrm{H} 3 \mathrm{c}$ of $\mathrm{H} 3$ were tenable, which means not only the assumption that the more low carbon economic cost paid by logistics enterprises the more beneficial it was to promote low carbon Logistics, but also the supposition that the more guiding influence of low carbon policies and regulations the more beneficial it was to promote low carbon Logistics are confirmed. While the hypothesis $\mathrm{H} 3 \mathrm{~b}$ that the greater the low carbon social constraints faced by logistics enterprises are, the more beneficial it was to promote low carbon logistics was merely valid for low carbon operation behavior, the hypothesis $\mathrm{H} 3 \mathrm{~d}$ that the higher the low carbon technology maturity, the more beneficial it was to promote low carbon logistics was only established for low carbon input behavior.

\section{Conclusions and Suggestions}

The empirical results partly supported the hypothesis that low carbon logistics behavior was remarkably correlated with influence factors. According to the regression analysis, the main influential factors of low carbon logistics behavior were different and theinfluence degree might vary significantly since there is a great difference between the specific environmental behaviors of low carbon logistics.

The environmental values were significantly associated with low carbon logistics behavior among environmental attitude, and the stronger the environment value of logistics enterprise is, the more helpful it was to carry out low carbon logistics. It shows that the environmental values should be penetrated into all aspects of corporate environmental behavior and become the dominant ideology of low carbon investment behavior and low carbon operations behavior of logistics enterprises. Due to the lower popularity rate of low carbon technology knowledge, a lot of people do not have a clear cognition and concept about low carbon. Otherwise, since the ideology of conquering nature and extorting from nature is popular in the promotion of modern industrial revolution, value deviation among the group lies and there is considerable resistance in the formation and practice of environmental values. Therefore, the corporate environmental propaganda should be strengthened by applying the full power of the social, school, civil, or official and other agencies and by increasing publicity work of low carbon knowledge and skills to increase the popularization rate of environmental education from the quantity and to enrich the content of environmental education from the quality. Changing the traditional indoctrination education mode of environmental education, exerting the role of the nongovernmental environmental protection organization, expanding the environmental cultural industry chain, and promoting the logistics enterprise to change the extensive mode of development were needed to construct the environmental value that harmonizes between enterprises and the nature.

Among the personality characteristics of enterprise, low carbon logistics behavior has high correlation with low carbon behavior intention, low carbon behavior capability, group psychology, and self-efficacy. The stronger the low carbon intention, the low carbon capability, the group psychology, and the self-efficacy are, the more beneficial it was to promote low carbon Logistics. Through the analysis of correlation and regression, personality factors are the driving factors of low carbon operation behavior for logistics enterprises; that is to say, the low carbon operation behavior was driven by inner force. The low carbon consciousness and low carbon behavior intention of logistics enterprises are influenced by many factors such as the government, the market management standard, and enterprise managers, while the scale and technology ability of enterprise can affect the low carbon behavior ability. In order to upgrade the low carbon behavior ability, enterprises are ought to strengthen the cultivation of logistics enterprises' environment ability, to organize learning and communication, to spread the low carbon experience, raise the low carbon consciousness of enterprise managers, encourage low carbon technology innovation, and cultivate enterprise environment ability of development and maintenance in the future. To boost up the willingness of low carbon behavior of logistics enterprises, efforts should be made to perfect the liability regulations of environmental pollution, quantify the compensation standards of environmental pollution, promote environmental responsibility, and safeguard the environmental interests of enterprises, while, among situational factors, low carbon logistics behavior was significantly related to policies and regulations and economic cost. The more the guiding influence of low carbon policies and regulations is and the higher the low carbon cost are, the more beneficial it was to promote low carbon logistics. In particular, policies and regulations have significant effect on low carbon investment behavior and become the first consideration, reflecting that low carbon inputs behavior of logistics enterprises is a behavior driven by external forces and should continually play the role of the policies and regulations in the low carbon environment in the future. In order to provide a guarantee for low carbon logistics, increasing the investment of cleaner production and environmental pollution control through the restraint system, improving the process, refining and perfecting the regulations, and formulating corresponding preferential policies to encourage enterprises to carry out environmental 
protection training and publicity are in great need. It was needed to clear the reward means and procedures such as tax preferences and subsidies of low carbon and to encourage and guide the enterprises to make positive environmental management action by using the legal means and economic means such as tax, subsidy, and environmental legislation. Besides speeding up the construction of monitoring system, the irregular check of environmental protection was also needed to guide enterprises to low carbon invest and operate.

The object of the study is logistics enterprises. Compared with industrial enterprises, logistics enterprises scale is relatively small, levels of profitability is low, investment of capital, technology, and research is week, and the ability to withstand risks is lack, so the low carbon operation was affected by personality factors such as low carbon behavior ability, and external factors such as policies and regulations are the driving factors of low carbon investment. While the enterprise scale, period of investment return, and scientific research strength are all different, the general industrial enterprises will be more concerned about the personality factors in the process of low carbon input. The research found that environmental values were significantly associated with low carbon logistics, logistics behavior of low carbon invest is significantly affected by external factors such as social norms, and logistics behavior of low carbon operate is the internal driving behavior strongly affected by corporate personality factors such as low carbon behavior ability. The management implications of it is to give advice for government and logistics managers that in order to achieve low carbon logistics goal, environmental propaganda to establish value orientation, play actively the function of policies and regulations in the low carbon logistics, and continue to improve enterprise's ability and willingness of low carbon environment should be strengthened. One of the limitations of this study is that it only studies the common influence factors of low carbon environmental behavior and do not focus on the specific influence factors such as the scale of enterprise and enterprise culture, which might affect the explanatory ability of the regression model more or less. Otherwise, this study is focused on developing low carbon logistics behavior scale and measuring the effects of the three types of influence factors, but it has yet to explore the relationship among variables. The relationship among variables and their impact should be studied and the influence factors such as enterprise culture, type, and scale should be concerned in the future research.

\section{Conflict of Interests}

The authors declare that there is no conflict of interests regarding the publication of this paper.

\section{Acknowledgments}

This paper is the stage results of two subjects funded by Zhejiang Modern Service Research Center, which is a philosophy and social sciences supporting research base in Zhejiang province. The two subjects are low carbon logistics development pathway below e-commerce economy and the mechanism of the effects of e-commerce on low carbon logistics on the background of symbiotic relationship.

\section{References}

[1] H.-D. Waisman, C. Guivarch, and F. Lecocq, "The transportation sector and low-carbon growth pathways: modelling urban, infrastructure, and spatial determinants of mobility," Climate Policy, vol. 13, no. 1, pp. 106-129, 2013.

[2] P. Oberhofer and E. Furst, "Environmental management in the transport sector: findings of a quantitative survey," EuroMed Journal of Business, vol. 7, no. 3, pp. 268-279, 2012.

[3] Y. L. Wang and H. Jiang, "The theoretical frames and evolutionary logic analysis of the enterprise environment behavior," Foreign Economic and Management, vol. 8, pp. 26-34, 2012.

[4] I. Ajzen, "From intentions to actions: a theory of planned behavior," in Action Control, J. Kuhi and J. Beckmann, Eds., SSSP Springer Series in Social Psychology, pp. 11-39, Springer, Heidelberg, Germany, 1985.

[5] I. Ajzen and T. J. Madden, "Prediction of goal-directed behavior: attitudes, intentions, and perceived behavioral control," Journal of Experimental Social Psychology, vol. 22, no. 5, pp. 453-474, 1986.

[6] I. Ajzen, "The theory of planned behavior," Organizational Behavior and Human Decision Processes, vol. 50, no. 2, pp. 179211, 1991.

[7] P. C. Stern and T. Dietz, "The value basis of environmental concern," Journal of Social Issues, vol. 50, pp. 65-84, 1994.

[8] P. C. Stern, T. Dietz, T. Abel, G. A. Guagnano, and L. Kalof, "A value-belief-norm theory of support for social movements: the case of environmentalism," Human Ecology Review, vol. 6, no. 2, pp. 81-97, 1999.

[9] P. C. Stern, "Toward a coherent theory of environmentally significant behavior," Journal of Social Issues, vol. 56, no. 3, pp. 407-424, 2000.

[10] G. A. Guagnano, P. C. Stern, and T. Dietz, "Influences on attitude-behavior relationships: a natural experiment with curbside recycling," Environment and Behavior, vol. 27, no. 5, pp. 699-718, 1995.

[11] H. Kotzab, H. M. Munch, B. de Faultrier, and C. Teller, "Environmental retail supply chains: when global Goliaths become environmental Davids," International Journal of Retail and Distribution Management, vol. 39, no. 9, pp. 658-681, 2011.

[12] R. E. Dunlap, "Environmental s ociology: a personal perspective on its first quarter century," Organization and Environment, vol. 15, no. 1, pp. 10-29, 2002.

[13] P. Wesley Schultz and L. Zelezny, "Values as predictors of environmental attitudes: evidence for consistency across 14 countries," Journal of Environmental Psychology, vol. 19, no. 3, pp. 255-265, 1999.

[14] J. Thøgersen and F. Ölander, "To what degree are environmentally beneficial choices reflective of a general conservation stance?” Environment \& Behavior, vol. 38, no. 4, pp. 550-569, 2006.

[15] A. M. Nordlund and J. Garvill, "Value structures behind proenvironmental behavior," Environment \& Behavior, vol. 34, no. 6, pp. 740-756, 2002.

[16] J. M. Hines, H. R. Hungerford, and A. N. Tomera, "Analysis and synthesis is of research on responsible environmental behavior: a meta-analysis," The Journal of Environmental Education, vol. 18 , no. 2, pp. 1-8, 1986. 
[17] T. Gärling, S. Fujii, A. Gärling, and C. Jakobsson, "Moderating effects of social value orientation on determinants of proenvironmental behavior intention," Journal of Environmental Psychology, vol. 23, no. 1, pp. 1-9, 2003.

[18] F. G. Kaiser, S. Wölfing, and U. Fuhrer, "Environmental attitude and ecological behaviour," Journal of Environmental Psychology, vol. 19, no. 1, pp. 1-19, 1999.

[19] L. M. Andersson and T. S. Bateman, "Individual environmental initiative: championing natural environmental issues in U.S. business organizations," Academy of Management Journal, vol. 43, no. 4, pp. 548-570, 2000.

[20] D. A. Waldman and D. Siegel, "Defining the socially responsible leader," Leadership Quarterly, vol. 19, no. 1, pp. 117-131, 2008.

[21] M. D. López-Gamero, E. Claver-Cortés, and J. F. Molina-Azorín, "Complementary resources and capabilities for an ethical and environmental management: a qual/quan study," Journal of Business Ethics, vol. 82, no. 3, pp. 701-732, 2008.

[22] C.-Y. Lin and Y.-H. Ho, “The influences of environmental uncertainty on corporate green behavior: an empirical study with small and medium-size enterprises," Social Behavior and Personality, vol. 38, no. 5, pp. 691-696, 2010.

[23] C. Lee and R. T. Green, "Cross-cultural examination of the Fishbein behavior intention model," Journal of International Business Studies, vol. 22, no. 2, pp. 289-305, 1991.

[24] G. T. S. Ho, K. L. Choy, C. H. Y. Lam, and D. W. C. Wong, "Factors influencing implementation of reverse logistics: a survey among Hong Kong businesses," Measuring Business Excellence, vol. 16, no. 3, pp. 29-46, 2012.

[25] A. Biglan, "The role of advocacy organizations in reducing negative externalities," Journal of Organizational Behavior Management, vol. 29, no. 3, pp. 215-230, 2009.

[26] M. Fu, "The environmental Kuznets curve in China: morphology, inflection point and influence factors," Quantitative \& Technical Economics, vol. 11, pp. 40-50, 2008.

[27] C.-Y. Lin and Y.-H. Ho, "RFID technology adoption and supply chain performance: an empirical study in China's logistics industry," Supply Chain Management, vol. 14, no. 5, pp. 369-378, 2009.

[28] S. X. Li, "Preference, technology and the environment Kuznets curve," Journal of Zhongnan University of Economics and Law, vol. 1, pp. 31-38, 2012.

[29] R. E. Dunlap, K. D. V. Liere, A. G. Mertig, and R. E. Jones, "Measuring endorsement of the new ecological paradigm: a revised NEP scale," Journal of Social Issues, vol. 56, no. 3, pp. 425-442, 2000.

[30] J. Frick, F. G. Kaiser, and M. Wilson, "Environmental knowledge and conservation behavior: exploring prevalence and structure in a representative sample," Personality and Individual Differences, vol. 37, no. 8, pp. 1597-1613, 2004.

[31] R. Y. K. Chan, "Determinants of Chinese consumers'green purchase behavior," Psychology and Marketing, vol. 18, no. 4, pp. 389-413, 2001.

[32] M. Sherer, J. E. Maddux, B. Mercandante, B. Jacobs, and R. W. Rogers, "The self-efficacy scale: construction and validation," Psychological Reports, vol. 51, pp. 663-671, 1982.

[33] C. Tanner and S. W. Kast, "Promoting sustainable consumption: determinants of green purchases by Swiss consumers," Psychology and Marketing, vol. 20, no. 10, pp. 883-902, 2003. 


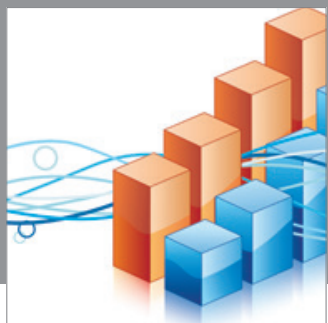

Advances in

Operations Research

mansans

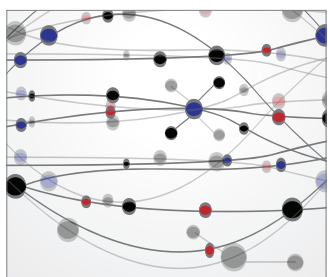

The Scientific World Journal
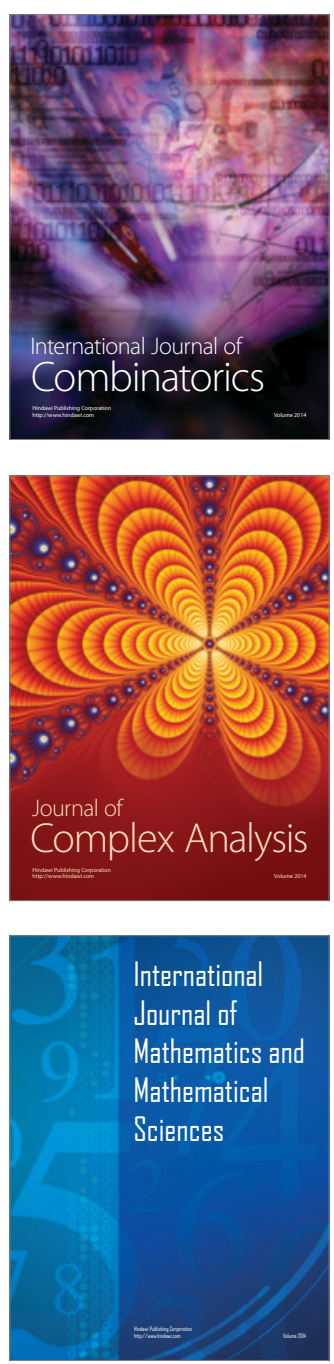
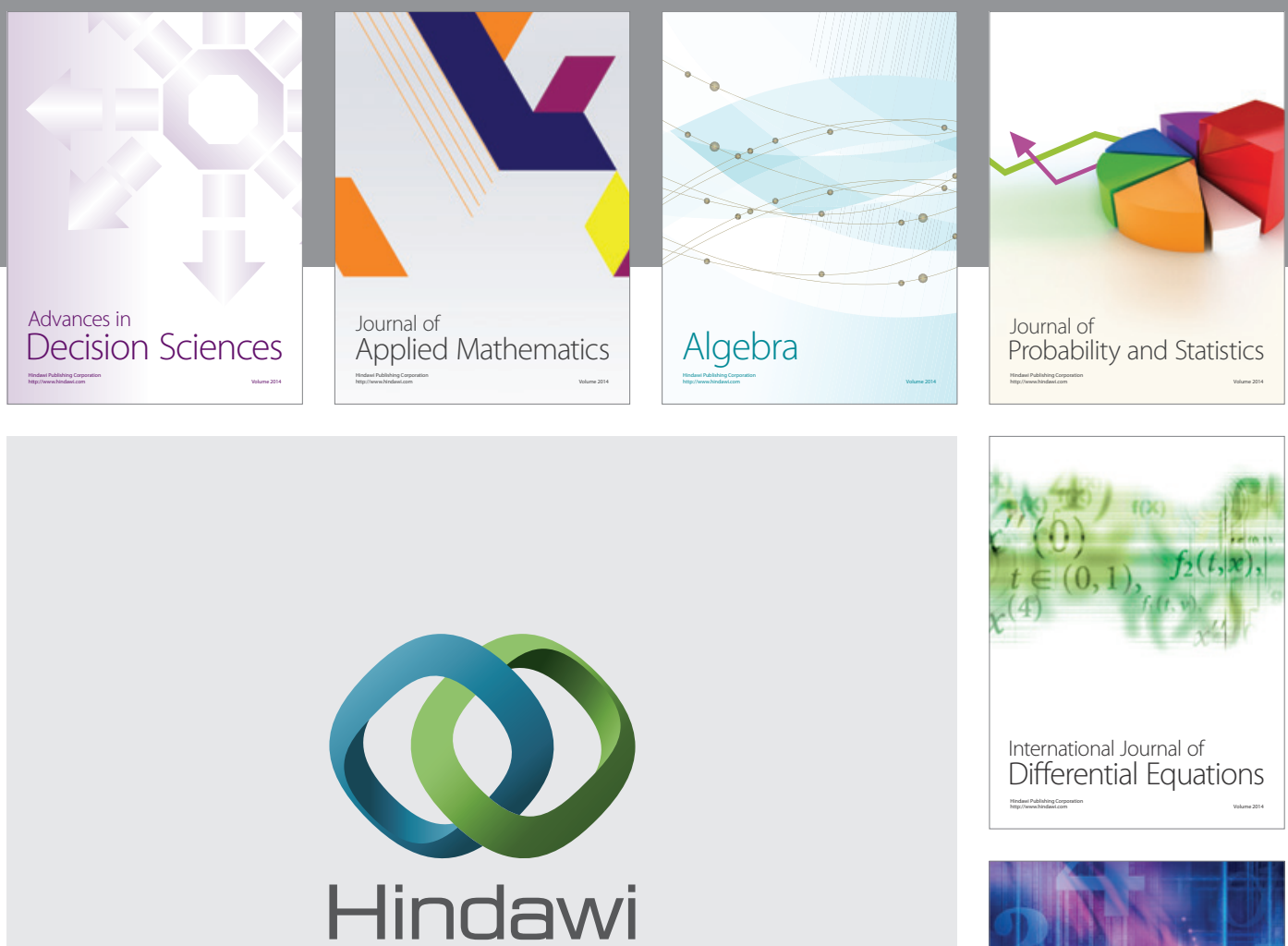

Submit your manuscripts at http://www.hindawi.com
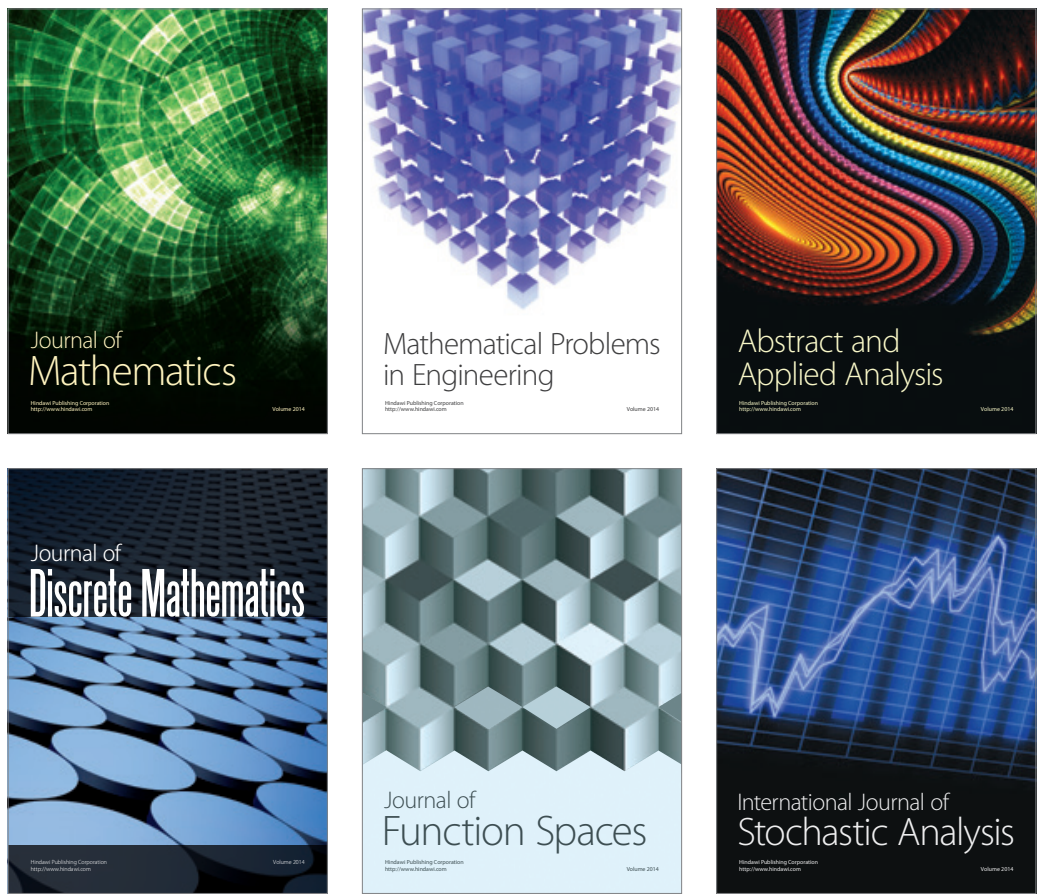

Journal of

Function Spaces

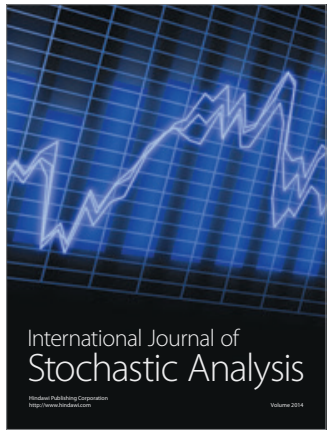

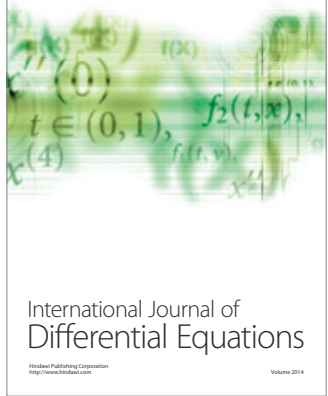
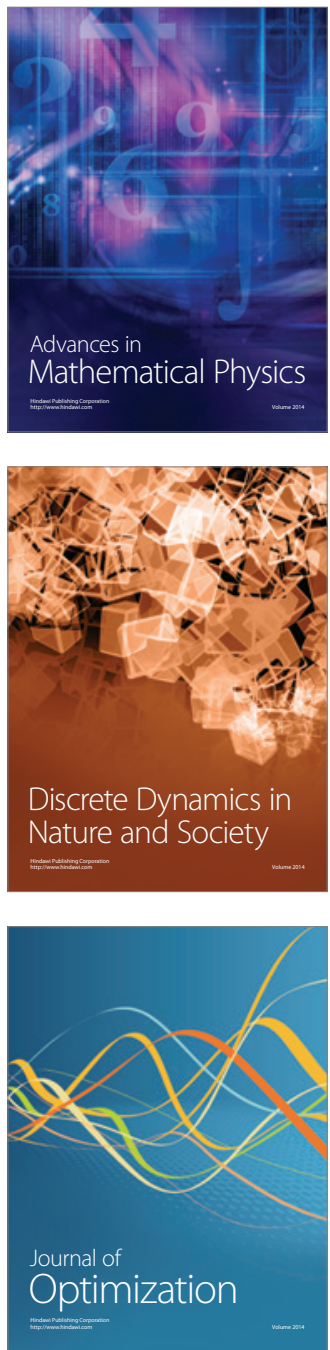